\title{
Dynamic Relatedness Analysis of Three Exchange Rate Markets' Volatility: Study of Korea, Taiwan and Thailand
}

\author{
Wann-Jyi Horng ${ }^{1}$, Tien-Chung $\mathrm{Hu}^{2}{ }^{2}$ \\ ${ }^{1}$ Department of Hospital and Health Care Administration, Chia Nan University of Pharmacy \& Science, Tainan 71710, Taiwan \\ ${ }^{2}$ Department of Mathematics, National Tsing Hua University, Hsinchu 300, Taiwan \\ hwj7902@mail.chna.edu.tw
}

\begin{abstract}
This paper studies the association and the model construction of the Korea's, the Taiwan's and the Thailand's exchange rate markets. In this paper we can construct a dynamic conditional correlation (DCC) and a trivariate $\operatorname{IGARCH}(1,2)$ model to evaluate the association and there are not exist an asymmetrical effect among the three exchange rate markets. The empirical results of correlation analysis also show that Korea exchange rate market positively affects the Taiwan's and the Thailand's exchange rate markets, and the volatility of the three exchange rate market interact with one another. Furthermore, for example, the variation risk of the Korea exchange rate markets' volatility affects the variation risks of the Taiwan and Thailand exchange rate markets. The empirical result suggests that the investors or international fund managers of the exchange rate markets must evaluate their markets on the previous of the exchange rate investment decision. They also need to consider the risk and relationship of the three exchange rate markets' volatility.

Index Terms - exchange rate market, asymmetrical effect, DCC, trivariate IGARCH model.
\end{abstract}

\section{Introduction}

We know that Korea's economical physique belongs partly to an island economy, where positive includes to the foreign trade unfolds where ties between Thailand and Taiwan are close. We know that Korea is one of Asian four dragons, also Korea economy of growth in 2006 is 5\%, and the forecast value of the grow rate is $4.3 \%$ in the future. We also know that Thailand is also the major economical financial system in the Association of South-east Asia Nations. Thailand and Taiwan have a close relationship with the Korea based on the trade and the circulation of capital, and the Thailand is the most powerful global economic nation in the Association of Southeast Asia Nations. Therefore, how these three stock markets impact one another is certainly worth further discussion.

Among the financial time series non-linearity research literatures, Engle 9 proposes the autoregressive conditionally heteroskedasticity (called $\mathrm{ARCH}$ ) model and Bollerslev ${ }^{3}$ offers the generalization autoregressive conditionally heteroskedasticity (called GARCH) model. These two models can catch the financial properties when the conditional variance is not a fixed parameter. Nelson ${ }^{18}$ looks at stock price changes and discovers that they have both positive and negative relationships with the future stock price volatility.

The GARCH model supposes a settled time conditional variance for the preceding issue of conditional variance and an error term square function. Therefore, the error term's positive and negative values do not respond to its influence on the conditional variance equation. The conditional variance only changes along with the error term's value change, and cannot go along with the error term's positive and negative changes. To improve this flaw, Nelson ${ }^{19}$ presents an exponential GARCH model and Glosten, Jaganathan, and Runkle ${ }^{12}$ give a GJR-GARCH model. These model are the so-called the models of asymmetric GARCH. There are many research studies on the asymmetric problem, such as Brooks ${ }^{2}$, Poon and Fung $^{20}$, Campell and Hentschel ${ }^{6}$, Koutmos and Booth ${ }^{14}$, and Koutmos $^{15}$. These studies expand the research methods of the return volatility between stock markets. For statements on the multivariate GARCH model, scholars such as Yang ${ }^{24}$, Yang and Doong ${ }^{23}$, Granger, Hung and Yang ${ }^{11}$, Wang and Barrett ${ }^{22}$ (2002) and Bollerslev ${ }^{4}$ proposes the bivariate GARCH model.

The main goal of this paper is to discuss the association of the Korea, the Taiwan, and the Thailand's exchange rates' volatility. The paper constructs the DCC and the trivariate GARCH theoretical model and examines whether or not there is an asymmetrical influence between the markets. We understand there possibly creates an influence on the three exchange rate markets, by using the multivariate Normal distribution for the stochastic error term. We also use the maximum likelihood algorithm method of BHHH (Berndt et. al. ${ }^{5}$ ) to estimate the parameters of the proposed model. The organization of this paper is as follows. Section 2 states the data characteristics. Section 3 provides the proposed model and the empirical results. Section 4 provides the asymmetrical test of the proposed model and the last section gives the conclusion.

\section{Data Characteristics}

\section{A. Data Sources}

This research discusses the exchange rate returns in the Korea, the Taiwan, and the Thailand and whether there is an association of the three exchange rate markets' volatility on each other. In the sample selection, this research uses the Korea exchange rate, Taiwan exchange rate, Thailand exchange rate as the sample. We select the sample period from January, 2001 to December, 2009 and use the exchange rate prices for all the dates. The data originate from the DataStream, a large database in Taiwan.

\section{B. Volatility Rate Calculation and Trend Charts}

In order to compute the exchange rate volatility rates, this 
paper adopts the natural logarithm of the exchange rate for every exchange rate market sample $\left(K E R_{t}, T W E R_{t}, T H E R_{t}\right)$ with one step difference and then multiplied by 100 - namely, for the Korea's exchange rate market, the exchange rate volatility rates are

$$
R K E R_{t}=100 *\left[\ln \left(K E R_{t}\right)-\ln \left(K E R_{t-1}\right)\right] .
$$

For the Taiwan's exchange rate market, the exchange rate volatility rates are

$$
R T W E R_{t}=100 *\left[\ln \left(T W E R_{t}\right)-\ln \left(T W E R_{t-1}\right)\right] .
$$

Finally, for the Thailand's exchange rate market, the exchange rate volatility rates are

$$
\text { RTHER }_{t}=100 *\left[\ln \left(\text { THER }_{t}\right)-\ln \left(\text { THER }_{t-1}\right)\right] .
$$

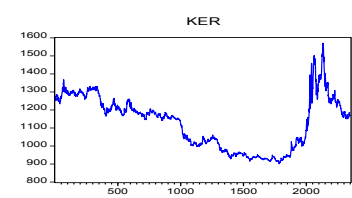

THER
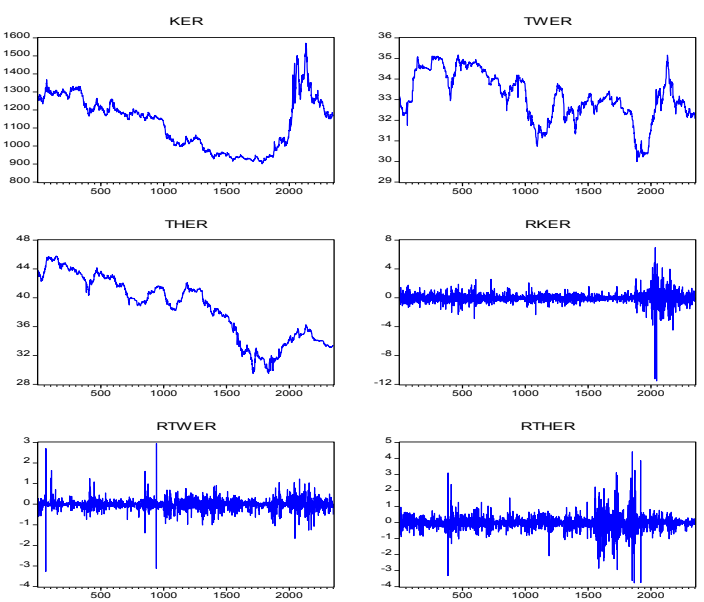

RKER

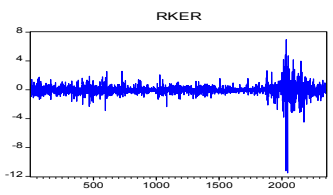

RTHER

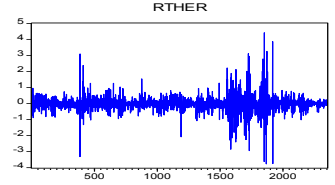

Figure 1. Trend charts of the Korea, Taiwan and Thailand's exchange rates, and trend charts of the Korea, Taiwan and Thailand's exchange rate volatilities.

From Figure 1, we may see that the Korea, the Taiwan and the Thailand's exchange rates presents obviously the same direction of trend. From Figure 1, we also know that the volatility of these three exchange rate market returns have a volatility clustering phenomenon. We may also know that the Korea exchange rate market, the Taiwan exchange rate market and the Thailand exchange rate market have certain relevances on their return volatility processes. This also means that there are the mutual relations among these three exchange rate markets. This is also mainly the main motivation for discussing the relationships among the Korea, the Taiwan and the Thailand's exchange rate volatilities.

\section{Basic Statistics and Some Tests}

The return rates of the exchange rates in the Korea, the Taiwan and the Thailand show a stationary state sequence. Table 1 shows some basic statistical analysis: mean value, standard deviation, kurtosis coefficient, skewed coefficient, and normal distribution examination. From Table 1, the average rate of return of the Korea's exchange rate is -0.0035 , the average rate of return of the Taiwan's exchange rate is 0.0014 , and the average rate of return of the Thailand's exchange rate is -0.0112 . The variation risk of the Korea's exchange rate return rate is 0.7768 , the variation risk of the Taiwan's exchange rate return rate is 0.2772 , and the variation risk of the Thailand's exchange rate return rate is 0.4834 , and therefore the variation risk of the Korea's exchange rate return rate is the highest. From the Jarque-Bera statistics, under the null hypotheses of the normal distribution, we discover that the three exchange rate return rates do not show a normal distribution. Moreover, the kurtosis is bigger than 3, and this demonstrates that the data have the phenomena of a heavy tail distribution. When the sample size is large enough, the heavy tail distribution will approximate the normal distribution.

Table 1. Data Statistics

\begin{tabular}{|l|l|l|l|}
\hline Statistic & RKER & RTWER & RTHER \\
\hline Mean & -0.003468 & -0.001400 & -0.011205 \\
\hline S-D & 0.776827 & 0.277199 & 0.483421 \\
\hline Skewed & -2.027566 & -0.392015 & 0.244265 \\
\hline Kurtosis & 50.16095 & 30.15591 & 20.50981 \\
\hline J-B N & 219205.3 & 72206.67 & 30018.40 \\
(p-value) & $(0.0000)$ & $(0.0000)$ & $(0.0000)$ \\
\hline sample & 2348 & 2348 & 2348 \\
\hline
\end{tabular}

Notes: (1) S-D denotes the standard deviation of data.

(2) J-B N denotes the normal distribution test of Jarque-Bera.

(3) p-value $<\alpha$ denotes significance $(\alpha=1 \%, \alpha=5 \%, \alpha=10 \%)$.

In order to match the suitable model, at first one may determine the stability of the time series data, as well as avoid the non-stationary state of the time series sequences and reduce the mistake of the empirical result. To do so, this paper uses the unit root tests of ADF (Dickey-Fuller ${ }^{7-8}$ ) and KSS (Kapetanios et al. ${ }^{16}$ ). The ADF and KSS examination results are omitted here. It shows that the Korea, Taiwan and Thailand's exchange rates do have stationary state sequences.

Under the co-integration test of Johansen ${ }^{13}$, we know that $\lambda_{\text {max }}$ and the Trace statistics are not significant under the level $5 \%$, the detail is omitted. This demonstrates that the exchange rates of the three exchange rate markets do not have a cointegration relationship altogether. Therefore, the Korea, the Taiwan and the Thailand's exchange rate markets do not have the long-term co-integration relationship, these three markets can really affect one another. Empirical result also shows that Korea, Taiwan and Thailand exchange rate markets have a relationship, based on the unconditional correlation coefficient. Therefore, we go a step further to understand the interactions of the three exchange rate markets.

\section{Arch Effect Test}

This paper further uses the ARCH effect test to determine the stock return volatility and whether there is the conditionally heteroskedasticity phenomenon. This research implements the Ljung-Box ${ }^{17}$ test method, the Lagrange Multiplier (LM) test method of Engle ${ }^{9}$, and the F distribution test method of Tsay $^{21}$ to further confirm the variance of the residual error sequence and whether there is an $\mathrm{ARCH}$ effect, and then if there is an ARCH effect we use the GARCH model to match it suitably. The ARCH effect test takes the residual error square of the past q periods to carry on the regression 
analysis. The ARCH effect test is based on the AR model in the next section.

We next implement the LM, F, and Ljung-Box (L-B) test methods to examine the exchange rate returns and to determine whether there is a conditionally heteroskedasticity phenomenon. The results of the ARCH effect test for the three exchange rate markets are listed in Table 2. The results show that the three exchange rate volatility rates have the conditionally heteroskedasticity phenomenon. This suggests that it matches suitably and it could use the GARCH model to analyze the data.

Table 2. ARCH Effect Test for Korea - Taiwan and Thailand Exchange Rate Markets (lag=30)

\begin{tabular}{|l|l|l|l|l|}
\hline RKER & $\begin{array}{l}\text { Engle LM } \\
\text { test }\end{array}$ & $\begin{array}{l}\text { Tsay F } \\
\text { test }\end{array}$ & $\begin{array}{l}\text { L-B test } \\
L B^{2}(1)\end{array}$ & $L B^{2}(3)$ \\
\hline Statistic & 809.564 & 40.923 & 8.602 & 9.806 \\
\hline (p-value) & $(0.0000)$ & $(0.0000)$ & $(0.0000)$ & $(0.0000)$ \\
\hline RTWER & $\begin{array}{l}\text { Engle LM } \\
\text { test }\end{array}$ & $\begin{array}{l}\text { Tsay F } \\
\text { test }\end{array}$ & $\begin{array}{l}\text { L-B test } \\
L B^{2}(1)\end{array}$ & $L B^{2}(2)$ \\
\hline Statistic & 477.660 & 19.789 & 24.274 & -10.541 \\
\hline (p-value) & $(0.0000)$ & $(0.0000)$ & $(0.0000)$ & $(0.0000)$ \\
\hline RTHER & $\begin{array}{l}\text { Engle LM } \\
\text { test }\end{array}$ & $\begin{array}{l}\text { Tsay F } \\
\text { test }\end{array}$ & $\begin{array}{l}\text { L-B test } \\
L B^{2}(1)\end{array}$ & $L B^{2}(4)$ \\
\hline Statistic & 511.424 & 21.583 & 14.382 & 9.075 \\
\hline (p-value) & $(0.0000)$ & $(0.0000)$ & $(0.0001)$ & $(0.0000)$ \\
\hline
\end{tabular}

Notes: $\mathrm{p}$-value $<\alpha$ denote significance $(\alpha=1 \%, \alpha=5 \%, \alpha=10 \%)$.

\section{Proposed Model}

This section uses the trivariate GARCH model- namely, it takes the (1)-(13) type to discuss the Korea, the Taiwan and the Thailand's exchange rate volatilities' relatedness analysis. The parameters' estimation first considers a general model and is based on the estimated results. We then deletes some not so significant constant items. Finally, we obtains a simplification model for the Korea, the Taiwan and the Thailand's exchange rate volatilities' relatedness analysis. From the empirical diagnosis results, we know that the Korea, the Taiwan and the Thailand's exchange rate volatility rates may be constructed on the trivariate $\operatorname{GARCH}(1,2)$ model with a DCC, the estimate results are stated in Table 3. The proposed model is given as follows:

$$
\begin{aligned}
\text { RKER }_{t}= & \phi_{0}+\phi_{11} \text { RKER }_{t-1}+\phi_{21} \text { RTWER }_{t-1} \\
& +\phi_{31} \text { RTHER }_{t-1}+a_{1, t} \\
\text { RTWER }_{t}= & \varphi_{0}+\varphi_{11} \text { RKER }_{t-1}+\varphi_{21} \text { RTWER }_{t-1} \\
& +\varphi_{31} \text { RTHER }_{t-1}+a_{2, t} \\
\text { RTHER }_{t}= & \psi_{0}+\psi_{11} \text { RKER }_{t-1}+\psi_{21} \text { RTWER }_{t-1} \\
& +\psi_{31} \text { RTHER }_{t-1}+a_{3, t} \\
h_{11, t}= & \alpha_{10}+\alpha_{11} a_{1, t-1}^{2}+\beta_{11} h_{11, t-1}
\end{aligned}
$$

$$
\begin{aligned}
& h_{22, t}=\alpha_{20}+\alpha_{21} a_{2, t-1}^{2}+\alpha_{22} a_{2, t-2}^{2}+\beta_{21} h_{22, t-1} \\
& h_{33, t}=\alpha_{30}+\alpha_{31} a_{3, t-1}^{2}+\beta_{31} h_{33, t-1} \\
& q_{12, t}=c_{0}+c_{1} \rho_{12, t-1}+c_{2} a_{1, t-1} a_{2, t-1} / \sqrt{h_{11, t-1} h_{22, t-1}} \\
& q_{13, t}=d_{0}+d_{1} \rho_{13, t-1}+d_{2} a_{1, t-1} a_{3, t-1} / \sqrt{h_{11, t-1} h_{33, t-1}} \\
& q_{23, t}=e_{0}+e_{1} \rho_{23, t-1}+e_{2} a_{2, t-1} a_{3, t-1} / \sqrt{h_{22, t-1} h_{33, t-1}} \\
& \rho_{12, t}=\exp \left(q_{12, t}\right) /\left(\exp \left(q_{12, t}\right)+1\right) \\
& \rho_{13, t}=\exp \left(q_{13, t}\right) /\left(\exp \left(q_{13, t}\right)+1\right) \\
& \rho_{23, t}=\exp \left(q_{23, t}\right) /\left(\exp \left(q_{23, t}\right)+1\right) \\
& h_{12, t}=\rho_{12, t} \sqrt{h_{11, t}} \sqrt{h_{22, t}}, \\
& h_{13, t}=\rho_{13, t} \sqrt{h_{11, t}} \sqrt{h_{33, t}}, \\
& h_{23, t}=\rho_{23, t} \sqrt{h_{22, t}} \sqrt{h_{33, t}} \\
& a_{t}^{\prime}\left(a_{1, t}, a_{2, t}, a_{3, t}\right) \quad \text { obeys the trivariate } \\
& \text { normal }
\end{aligned}
$$

distribution- namely, $N\left(\overrightarrow{0}, H_{t}\right)$, among $\overrightarrow{0}^{\prime}=(0,0,0)$ and

$$
\begin{aligned}
& H_{t}=\left[\begin{array}{lll}
h_{11, t} & h_{21, t} & h_{31, t} \\
h_{12, t} & h_{22, t} & h_{32, t} \\
h_{13, t} & h_{23, t} & h_{33, t}
\end{array}\right], \quad h_{12, t}=h_{21, t} \quad, \quad h_{13, t}=h_{31, t}, \\
& h_{23, t}=h_{32, t} .
\end{aligned}
$$

The probability density function of $\vec{a}_{t}$ can refer the book of Tsay (2004). Here $\rho_{12, t}$ is the dynamic conditional correlation (DCC) coefficient of $a_{1, t}$ and $a_{2, t}, \rho_{13, t}$ is the DCC coefficient of $a_{1, t}$ and $a_{3, t}, \rho_{23, t}$ is the DCC coefficient of $a_{2, t}$ and $a_{3, t}$.

By the estimated results of the trivariate $\operatorname{GARCH}(1,2)$ model with a DCC in Table 3, we test the estimated value of the parameters' coefficient to be significant or not with a Pvalue. In the sample period, the Korea's exchange rate volatility receives the previous one day's influence from the Korea's exchange rate market ( $\phi_{11}=-0.0716$ ). The Korea's exchange rate volatility receives the previous one day's impact from the Taiwan's exchange rate market $\left(\phi_{21}=0.0933\right)$. The Korea's exchange rate volatility receives the previous one day's impact from the Thailand's exchange rate market 
$\left(\phi_{31}=0.0899\right)$. The Taiwan's exchange rate volatility receives the previous one day's influence from the Korea's exchange rate market $\left(\varphi_{11}=0.0594\right)$. The Taiwan's exchange rate volatility does not receive the previous one day's influence of the Taiwan's exchange rate market. The Taiwan's exchange rate volatility also receives the previous one day's influence from the Thailand's exchange rate market $\left(\varphi_{31}=0.1023\right)$. The Thailand's exchange rate vplatility receives the previous one day's influence of the Korea's exchange rate market ( $\left.\psi_{11}=0.0263\right)$, the Thailand's exchange rate volatility receives the previous one day's influence of the Taiwan's exchange rate market $\left(\psi_{21}=0.0798\right)$, and it receives the previous one day's influence of the Thailand's exchange rate market $\left(\psi_{31}=-0.0785\right)$. From the empirical results as above, we also know that these three exchange rate markets do have the relationships.

On the other hand, the DCC average estimation value of the Korea and the Taiwan exchange rate volatilities is significant $\left(\hat{\bar{\rho}}_{12}=0.4475\right)$. This result means the Korea exchange rate's volatility has a positive influence to the Taiwan exchange rate's volatility, and they are precisely a synchronized mutual influence. When the variation risk of the Korea exchange rate volatility rate increases, the investor's risk in the Taiwan exchange rate market is able to increase. Likewise, when the variation risk of the Korea exchange rate volatility rate falls, the investor's risk in the Taiwan exchange rate market is also able to be reduced. Similarly, the DCC average estimation value of the Korea and the Thailand exchange rate volatilities is significant ( $\hat{\bar{\rho}}_{13}=0.3248$ ). The DCC average estimation value of the Taiwan and the Thailand exchange rate volatilities is also significant $\left(\hat{\bar{\rho}}_{23}=0.2928\right)$. As an example, for the Korea exchange rate market, the risk of its exchange rate receives the influence from the Taiwan exchange rate market and the influence is the bigger than that of the Thailand market.

The observed conditional variance equation of the estimated coefficient, under the $10 \%$ significance level, demonstrates that all the conditional variance estimated coefficients are significance in Table 3. This result works when the exchange rate volatility rate of the Korea, the Taiwan, and the Thailand are different to the traditional GARCH model with a constant conditional correlation. The previous one days' residual error square item and the previous one day's conditional variance will affect the Korea, the Taiwan, and the Thailand's exchange rate volatility rate volatilities and also can produce the different variation risks, among which, $\alpha_{11}+\beta_{11}=1, \alpha_{21}+\alpha_{22}+\beta_{21}=1$, and $\alpha_{31}+\beta_{31}=1$. Also, $\alpha_{11}+\beta_{11}, \alpha_{21}+\alpha_{22}+\beta_{21}$, and $\alpha_{31}+\beta_{31}$ conforms to the parameter of the IGARCH model's conditional supposition. The empirical result also shows that the volatility of variation risk is the lowest $\left(\beta_{21}=0.5678\right)$ for the Taiwan's exchange rate market. The single variable GARCH and bivariate GARCH models are unable to respond to this information, but the DCC and the trivariate $\operatorname{GARCH}(1,2)$ model might truly catch the Korea, the Taiwan, and the Thailand's exchange rates' volatility process. Therefore, the explanatory ability of the trivariate $\operatorname{GARCH}(1,2)$ model with a DCC is better than the traditional models of the single variable and the bivariate GARCH.

Table 3. Parameter Estimation of the Trivariate $\operatorname{IGARCH}(1,2)$ Model with a DCC

\begin{tabular}{|l|l|l|l|l|}
\hline Parameter & $\phi_{11}$ & $\phi_{21}$ & $\phi_{31}$ & $\varphi_{11}$ \\
\hline Coefficient & -0.0716 & 0.0933 & 0.0899 & 0.0594 \\
\hline (p-value) & $(0.0011)$ & $(0.0056)$ & $(0.0000)$ & $(0.0000)$ \\
\hline Parameter & $\varphi_{21}$ & $\varphi_{31}$ & $\psi_{11}$ & $\psi_{21}$ \\
\hline Coefficient & -0.0068 & 0.0531 & 0.0263 & 0.0798 \\
\hline (p-value) & $(0.8085)$ & $(0.0000)$ & $(0.0171)$ & $(0.0078)$ \\
\hline Parameter & $\psi_{31}$ & $\alpha_{10}$ & $\alpha_{11}$ & $\beta_{11}$ \\
\hline Coefficient & -0.0785 & 0.0072 & 0.1389 & 0.8611 \\
\hline (p-value) & $(0.0032)$ & $(0.0000)$ & $(0.0000)$ & $(0.0000)$ \\
\hline Parameter & $\alpha_{20}$ & $\alpha$ & $\alpha$ & $\beta_{21}$ \\
\hline Coefficient & 0.0114 & 0.3638 & 0.0684 & 0.5678 \\
\hline (p-value) & $(0.0000)$ & $(0.0000)$ & $(0.0792)$ & $(0.0000)$ \\
\hline Parameter & $\alpha_{30}$ & $\alpha_{31}$ & $\beta_{31}$ & $c_{0}$ \\
\hline Coefficient & 0.0055 & 0.1666 & 0.8334 & 1.4447 \\
\hline (p-value) & $(0.0000)$ & $(0.0000)$ & $(0.0000)$ & $(0.0000)$ \\
\hline Parameter & $c_{1}$ & $c_{2}$ & $d_{0}$ & $d_{1}$ \\
\hline Coefficient & -3.5633 & -0.1977 & -2.0190 & 3.9229 \\
\hline (p-value) & $(0.0000)$ & $(0.0000)$ & $(0.0000)$ & $(0.0000)$ \\
\hline Parameter & $d_{2}$ & $e_{0}$ & $e_{1}$ & $e_{2}$ \\
\hline Coefficient & 0.0282 & -2.1917 & 4.1859 & 0.1787 \\
\hline (p-value) & $(0.0000)$ & $(0.0000)$ & $(0.0000)$ & $(0.0000)$ \\
\hline Parameter & $\bar{\rho}_{12, t}$ & $\min \rho_{12, t}$ & $\max \rho_{12, t}$ & $\bar{\rho}_{13, t}$ \\
\hline Coefficient & 0.4475 & 0.0151 & 0.9758 & 0.3248 \\
\hline (p-value) & $(0.0000)$ & & & $(0.0000)$ \\
\hline Parameter & $\max \rho_{13, t}$ & $\bar{\rho}_{23, t}$ & $\min \rho_{23, t}$ & $\max \rho_{23, t}$ \\
\hline Coefficient & 0.9140 & 0.2928 & 0.0607 & 0.9208 \\
\hline (p-value) & & $(0.0000)$ & & \\
\hline
\end{tabular}

Notes: (1) $\mathrm{p}$-value $<\alpha$ denotes significance $(\alpha=1 \%, \alpha=5 \%, \alpha=10 \%)$.

(2) The min $\rho_{t}$ denotes the minimum value of DCC coefficient, and the max $\rho_{t}$ denotes the maximum value of DCC coefficient.

The trivariate GARCH model is appropriate to examine the standard residual error and a standard residual error square series by the test method of Ljung-Box ${ }^{17}$ to see whether there still exists auto-correlation. Empirical result shows that the diagnosis presents that the DCC and the trivariate GARCH(1, 2) model already has no auto-correlation of the standard residual error. The DCC and the trivariate $\operatorname{GARCH}(1,2)$ model already does not have an ARCH effect of the standard 
residual error square series. Therefore, this model matches quite suitably and is appropriate.

\section{Asymmetric Test Of The Trivariate Garch Model}

Because of the parameter estimation and the standard residual error diagnosis in the above, the examination only can check if the model matches up with the suitable quality, but it actually is unable to look up whether the model has an asymmetrical phenomenon. Therefore, Engle and $\mathrm{Ng}^{10}$ develop a diagnosis test in order to examine whether the model has asymmetrical risk or not. This research uses this diagnosis test to carry out the examination. The examination method of the model hypotheses has the following four examination methods: (1) sign bias test (2) negative size bias test (3) positive size bias test (4) joint test. The test results are stated in Table 4.

Table 4. Asymmetric Test of the Trivariate GARCH Model

\begin{tabular}{|l|l|l|l|l|}
\hline Korea & $\begin{array}{l}\text { Sign bias } \\
\text { test }\end{array}$ & $\begin{array}{l}\text { Negative size } \\
\text { Bias test }\end{array}$ & $\begin{array}{l}\text { Positive size } \\
\text { Bias test }\end{array}$ & Joint test \\
\hline F statistic & 2.2704 & 0.3129 & 0.4110 & 1.1393 \\
\hline (p-value) & $(0.1320)$ & $(0.5759)$ & $(0.5215)$ & $(0.3318)$ \\
\hline Taiwan & $\begin{array}{l}\text { Sign bias } \\
\text { test }\end{array}$ & $\begin{array}{l}\text { Negative size } \\
\text { Bias test }\end{array}$ & $\begin{array}{l}\text { Positive size } \\
\text { Bias test }\end{array}$ & Joint test \\
\hline F statistic & 3.0898 & 0.1948 & 1.3398 & 1.6531 \\
\hline (p-value) & $(0.0789)$ & $(0.6590)$ & $(0.2472)$ & $(0.1751)$ \\
\hline Thailand & $\begin{array}{l}\text { Sign bias } \\
\text { test }\end{array}$ & $\begin{array}{l}\text { Negative size } \\
\text { Bias test }\end{array}$ & $\begin{array}{l}\text { Positive size } \\
\text { Bias test }\end{array}$ & Joint test \\
\hline F statistic & 2.2830 & 0.9208 & 0.2778 & 1.0910 \\
\hline (p-value) & $(0.1309)$ & $(0.3374)$ & $(0.5982)$ & $(0.3516)$ \\
\hline
\end{tabular}

Notes: p-value $<\alpha$ denotes significance

$$
(\alpha=1 \%, \alpha=5 \%, \alpha=10 \%) \text {. }
$$

From the positive size bias test and the joint test, we know that the exchange rate markets of the Korea, the Taiwan and the Thailand do not have an asymmetrical phenomenon in the sample period.

\section{Conclusions}

There are many factors that may influence exchange rate market, such as the overall economic agents and overall currency supplies, interest rates, prices, and inflation rates. Each factor can have an influence on the exchange rate volatilities. This research discusses three exchange rate market volatilities' influence of the Korea, the Taiwan and the Thailand. The empirical result shows that the Korea, the Taiwan and the Thailand's exchange rate volatilities may be constructed in the trivariate $\operatorname{IGARCH}(1,2)$ model with a DCC. This model also passes a standard residual error and the $\mathrm{ARCH}$ effect test, demonstrating that the trivariate $\operatorname{IGARCH}(1,2)$ model's fittings are appropriate. The empirical result also obtains that the average estimation value of DCC coefficient $\left(\hat{\bar{\rho}}_{12}=0.4475\right)$ of the Korea and Taiwan two exchange rate market volatilities is positive, the average estimation value of DCC coefficient $\left(\hat{\bar{\rho}}_{13}=0.3248\right)$ of the Korea and Thailand two exchange rate market volatilities is also positive, and the average estimation value of DCC coefficient ( $\hat{\bar{\rho}}_{23}=0.2928$ ) of the Taiwan and Thailand two exchange rate market volatilities is also positive. This result demonstrates that the Korea exchange rate volatility affects the Taiwan and Thailand exchange rate risks, and the Taiwan exchange rate volatility also affects the Korea and Thailand exchange rate risks. The empirical result also discovers that the Korea, the Taiwan and the Thailand's exchange rate market volatilities do not have the asymmetrical phenomenon in the sample period.

The theories and the models discussing on the return rate and the volatility properties of financial commodities are countless, and this research only uses the trivariate GARCH model to discuss the three exchange rate markets of the Korea, the Taiwan and the Thailand. The three exchange rate markets' volatility rate also shows the relationships. For future research, we suggest that the others multivariate GARCH models can be used for further analysis.

\section{References}

[1] H. Akaike, Information Theory and an Extension of the Maximum Likelihood Principle. In 2d. International Symposium on Information Theory, edited by B. N. Petrov and F. C. Budapest: Akademiai Kiado (1973), 267-281.

[2] C. Brooks, A Double-Threshold GARCH Model for the French Franc/Deutschmark Exchange Rate, Journal of Forecasting 20, 135 (2001).

[3] T. Bollerslev, Generalized autoregressive conditional hetroscedasticity, Journal of Econometrics 31, 307 (1986).

[4] T. Bollerslev, Modeling the coherence in short-run nominal exchange rates: a multivariate generalized ARCH model, Review of Economics and Statistics 72, 498 (1990).

[5] E. K. Berndt, B.H. Hall, R.E. Hall, and J.A. Hausman, Estimation and inference in nonlinear structural models, Annals of Economic and Social Measurement 4, 653 (1974).

[6] J.Y. Campell and L. Hentschel, No news is good news: an asymmetric model of changing volatility in stock returns, Journal of Financial Economic 31, 281 (1992).

[7] D.A. Dickey and W.A. Fuller, Distribution of estimates for autoregressive time series with a unit root, Journal of the American Statistical Association 74, 427 (1979).

[8] D.A. Dickey and W.A. Fuller, Likelihood Ratio Statistics for Autoregressive Time Series with a Unit Root, Econometrica 49, 1057 (1981).

[9] R.F. Engle, Autoregressive conditional heteroscedasticity with estimates of the variance of United Kingdom Inflation, Econometrica 50, 987 (1982).

[10] R.F. Engle and V.K. Ng, Measuring and testing the impact of news on volatility, Journal of Finance 45, 1749 (1993).

[11] C.W. Granger, J.B. Hung and C.W. Yang, A bivariate causality between stock prices and exchange rates: evidence from recent Asian Flu, The Quarterly Review of Economics and Finance 40, 337 (2000).

[12] L.R. Glosten, R. Jagannathan and D.E. Runkle, On the relation between the expected value and the volatility on the nominal excess returns on stocks, Journal of Finance 48, 1779 (1993).

[13] S. Johansen, Estimation and hypothesis testing of cointegration vector in gaussian vector autoregressive models, Econometrica 59, 1551 (1991).

[14] G. Koutmos and G.G. Booth, Asymmetric volatility transmission in international stock markets, Journal of International Money and Finance 14, 747 (1995).

[15] G. Koutmos, Modeling the dynamic interdependence of major European stock markets, Journal of Business Finance and Accounting 23, 975 (1996). 
[16] G. Kapetanios, Y. Shin and A. Snell, Testing for a unit root in the nonlinear STAR framework, Journal of Econometrics 112(2), 359 (2003).

[17] G.M. Ljung and G.E.P. Box, On a measure of lack of fit in time series models, Biometrika 65, 297 (1978).

[18] D.B. Nelson, Stationarity and persistence in the GARCH(1,1) model, Econometric Theory 6, 318 (1990).

[19] D.B. Nelson, Conditional heteroscedasticity in asset returns: A new Approach, Econometrica 59, 347 (1991).

[20] W.P.H. Poon and H.G. Fung, Red chip or H shares: Which Chinabacked securities process information the fastest?, Journal of Multinational Financial Management 10, 315 (2000).
[21] R.S. Tsay, Analysis of Financial Time Series, New York: John Wiley \& Sons, Inc (2004).

[22] K.L. Wang and C.B. Barrett, A new look at the trade volume effects of real exchange rate risk, Working paper in Cornell University (2002).

[23] S.Y. Yang and S.C. Doong, Price and volatility spillovers between stock prices and exchange rates: empirical evidence from the G-7 countries, International Journal of Business and Economics 3(2), 139 (2004).

[24] S.Y. Yang, A DCC analysis of international stock market correlations: the role of Japan on the Asian Four Tigers, Applied Financial Economics Letters 1(2), 89 (2005). 